\title{
Clínica dos gêneros não inteligíveis: Judith Butler e psicanálise
}

\section{Psicanálise e transexualismo: desconstruindo gêneros e patologias com Judith Butler.} PORCHAT, Patricia.

Curitiba: Juruá, 2014. 171 p.

É diante de uma questão nascida em sua própria clínica que a psicanalista Patricia Porchat escreve a tese de doutorado, defendida na Universidade de São Paulo em 2007, que resulta no livro Psicanálise e transexualismo: desconstruindo gêneros e patologias com Judith Butler. A questão consistia em saber qual noção de gênero possibilitaria uma posição mais ética, frente aos gêneros ditos não inteligíveis, que permitisse uma transformação nas pessoas, reduzindo os sofrimentos causados por um sentimento de inadequação de gênero.

Para responder a sua questão, Porchat decide acompanhar o percurso de Judith Butler - filósofa estadunidense feminista - em seus escritos sobre gênero. A escolha por essa autora não é casual. Porchat explica que Butler é uma autora sobre a qual têm sido feitos muitos debates e que causa polêmica em meios psicanalíticos. Além disso, essa autora articula suas reflexões sobre gênero à constituição do sujeito. Porchat revela também que as mudanças dos tipos de pacientes que buscam análise, as mudanças na sociedade e questões éticas a obrigam a reconstruir conceitos em sua clínica freudiana.

Para quem está por dentro do debate sobre a despatologização das identidades trans. a primeira coisa que chama a atenção é que apareça a palavra "transexualismo" no título do livro, uma vez que o sufixo - ismo - remete à patologia. É numa conversa com Porchat que se esclarece que sua opção original era "transexualidade", mas nos trâmites de publicação precisou ceder para dar lugar ao termo escolhido pela editora.

O livro é dividido em quatro capítulos. No primeiro capítulo, a autora trabalha a construção do conceito de gênero por duas vertentes: a teoria da construção social e a psicanálise. Inicia com as contribuições da teoria da construção social, desenvolvida por Michel Foucault, Jeffrey Weeks, Thomas Laqueur, entre outros. Essa teoria compreende que sexos, gêneros e identidades são necessariamente relacionados e dependentes do contexto sócio-histórico-cultural em que se desenvolvem, opondo-se à biologia e a concepções essencialistas. Por outro lado, algumas pessoas entendiam que essa teoria estaria se tornando determinista, normatizando identidades. No bojo dessa discussão, nasce a teoria queer - a qual hoje tem em Butler umas de suas principais representantes -, que, além de compreender todo comportamento como uma construção sócio-histórica, explicita a sexualidade como um dispositivo interpelado por estruturas de poder e dominação. Essa autora discute, ainda, os conceitos de dimorfismo sexual (que, de acordo com Thomas Laqueur, surge apenas no século XIX, possibilitando a ideia de sexo oposto) sexualidade, homo e heterossexualidade, e a distinção sexo/gênero.

Porchat traz esses autores entendendo que eles orientam a noção de gênero que Butler utiliza para interrogar a psicanálise, a qual herda a noção de que a diferença anatômica é fundamental na construção da subjetividade. Desse modo, a autora oferece fundamentos conceituais para que se compreendam os questionamentos a partir dos quais Butler parte, ou seja, oferece referências para a leitura dessa filósofa. Isso é muito interessante, na medida em 
que muitos de seus interlocutores, entre os quais Slavoj Zizek, afirmam que ela seria uma filósofa sem rigor teórico, pois autores e conceitos aos quais ela se refere não seriam tão claros e precisos em seu texto.

Na vertente da psicanálise, Porchat dialoga inicialmente com Freud, Karen Horney e Ernest Jones. Ela lembra que Freud, no início do século $\mathrm{XX}$, já fazia discussões relacionadas a gênero (embora não utilizasse o termo), buscando explicar como uma criança se transforma ou não em um homem masculino ou em uma mulher feminina, apontando não se tratar de um percurso natural. A autora aproxima, portanto, Freud e Butler, visto que ambos compreendem gênero como incoerente e descontínuo - os gêneros seriam não inteligíveis. No entanto, também esclarece que, enquanto Freud acredita na mescla do masculino com o feminino Butler pretende superar essa dicotomia, pois recusa o binarismo baseado no dimorfismo sexual.

Ademais, Porchat traz algumas contribuições do psicanalista Robert Stoller, que forjou o conceito de identidade de gênero na década de 1960. Debate, a partir de Nancy Chodorow e Juliet Mitchell, mostrando como essas psicanalistas descrevem a construção de gênero sem problematizar a hierarquização.

No capítulo dois, debate como o conceito de gênero questiona as categorias "masculino e feminino", "homem e mulher" na psicanálise e como esta também questiona essas noções, refletindo sobre que transformações o conceito produz na sociedade. Assim, tendo como referência Butler, o debate problematiza as relações de homo e heterossexualidade, visando uma transformação social que dê conta dos gêneros não inteligíveis. Para isso, Butler discute alguns conceitos psicanalíticos e, para compreender melhor a posição da filósofa, Porchat recorre a psicanalistas feministas que, usando o conceito de gênero, fazem críticas à psicanálise.

Inicialmente Porchat faz um breve histórico do conceito de gênero, baseando-se em Donna Haraway, e coloca a crítica de Butler de que o feminismo não fala dos gêneros não coerentes. A psicanálise feminista também não daria conta dos gêneros não inteligíveis, mas ofereceria algumas contribuições. Compreendendo isso, Porchat propõe o debate a partir de algumas feministas que refletem sobre gênero, como a antropóloga Gayle Rubin e as psicanalistas Nancy Chodorow, Jessica Benjamin e Emilce Dio Bleichmar, mas pondera que essas psicanalistas beiram uma concepção essencialista e de certo modo limitada em relação aos gêneros não inteligíveis. Por último, enfatiza o gênero como categoria política.

No terceiro capítulo, o que Porchat busca é apresentar as ideias de Butler referentes a gênero como ato performativo, de modo a preparar o leitor para o último capítulo, no qual aprofundará as tensões de Butler com relação à psicanálise. Explica que, para atingir seus objetivos políticos, que buscam dar visibilidade e cidadania aos gêneros não inteligíveis, Butler entende que não é suficiente criar um novo conceito de gênero, mas é necessário ir além, e interrogar as noções de simbólico e diferença sexual em Jacques Lacan.

Explica Porchat que, ao percorrer as questões ontológicas à luz de vários autores, o que Butler pretende é: "[...] encontrar uma noção de sujeito e uma noção de corpo, amarradas pela linguagem, que permitam incorporar na cultura, de modo não patológico, os seres humanos que não se enquadram nos padrões normais de gênero" (p. 82).

Butler vai encontrar na performatividade uma possibilidade de subversão do binarismo de gênero. A performatividade refere-se ao fato de que o ato torna real e produz aquilo que nomeia ou atua. Assim, se o gênero é um efeito performativo, sem essência, não revela identidade.

Ainda nesse capítulo, Porchat apresenta o recurso da paródia, utilizado por Butler. A paródia seria uma suposta imitação do original, por exemplo, a drag queen, a imitação de uma mulher. Mas Butler se vale da paródia para esvaziar a noção de original, dizendo que não há como pensar em originalidade, seja travesti ou "mulher de verdade" (p. 92).

Porchat apresenta também as discussões de Butler sobre o corpo, partindo de um corpo completamente determinado pela linguagem até um que possui partes que escapam à linguagem e é dirigido pela pulsão. Mostra como Butler recorre aos conceitos psicanalíticos ora para assimilá-los, ora para interrogá-los. Esclarece, ainda, que a tensão de Butler no que diz respeito à psicanálise é consequência de um confronto com os conceitos de diferença sexual e simbólico, os quais entenderia como reguladores e normativos das sexualidades ditas reconhecidas, e o conceito de pulsão, este que aponta para o fato de que somos dirigidos por algo que desconhecemos e que não se reduz à biologia, tampouco à cultura. Ou seja, ao mesmo tempo que critica aspectos compreendidos por ela como normativos, vê 
no conceito de pulsão a via de compreensão da sexualidade como aquilo que excede e ultrapassa a norma, ainda que não tome a sexualidade como completamente selvagem.

Há em Butler, segundo Porchat, uma clara intenção de encontrar recursos teóricos que permitam dar legitimidade ao humano, ainda que no processo de constituição subjetiva haja a questão da assunção de uma norma corporal, que esta assunção passe por identificações, mas destacando que estas identificações nem sempre resultam naquelas que satisfazem as normas.

Sua preocupação é discutir e questionar o que é considerado uma pessoa, entendendo que o abjeto se traduz por aquilo que é excluído quando se produz a diferença.

Uma nova fronteira de tensão entre a psicanálise de Millot e Butler com relação à indicação de cirurgia de redesignação sexual é apontada por Porchat. Millot advoga que é necessário um diagnóstico com relação à posição do sujeito em relação à castração simbólica, com a finalidade de avaliar as possibilidades de passar pela cirurgia sem surtar. O que Millot aponta é que, nas estruturas neuróticas, as oscilações da identidade de gênero são tributárias do caráter simbólico da identidade. Essas oscilações podem causar malestar, mas não há garantias de que com uma cirurgia essa identidade vá se fixar, pois se trata de uma questão de ordem simbólica, e não do corpo biológico. Isso seria diferente na estrutura psicótica, nos casos em que a identidade de gênero fosse da ordem delirante. Se a característica na neurose é duvidar, pela permanente substituição significante na ordem simbólica, na psicose o delírio fixa significações, por isso o caráter de certeza. Porchat diz que alguns psicanalistas, e aqui se refere à Millot e a Calligaris (p. 111), afirmam que a cirurgia em pessoas nas quais a identidade sexual é da ordem do delírio pode operar produzindo um efeito de estabilização na estrutura, diminuindo o risco de surto psicótico. O problemático, segundo a autora, teria sido o efeito do livro de Millot Extrasexo-, no qual aparecem esses argumentos, sobre a comunidade psicanalítica. Um efeito de associação da transexualidade com patologia.

Frente a esta problemática das cirurgias de redesignação sexual, que aponta quanto as pessoas buscam adequar-se à norma, Butler, segundo Porchat, propõe o cultivo das desidentificações coletivas, o que, segundo ela, poderia redundar em uma (re)conceitualização de quais são os corpos que importam.
No último capítulo, as questões de Butler com referência à diferença sexual e ao simbólico são aprofundadas por Porchat. Ela apresenta críticas dirigidas à Butler por Charles Shepherdson, Slavoj Zizek e Joan Copjec, e também as respostas. Em comum nesses autores, está a afirmação de que Butler critica conceitos que não compreende dentro da conceituação lacaniana. A imprecisão mais problemática seria a da diferença sexual em Lacan:

Segundo Zizek (1999), Butler não teria compreendido que, para Lacan, a 'diferença sexual' nunca pode ser propriamente simbolizada, transposta ou traduzida numa norma simbólica que fixa a identidade sexual do sujeito. Butler tornaria equivalente à 'diferença sexual' a norma simbólica heterossexual determinando o que é ser um 'homem' e o que é ser uma 'mulher'. [...]. A 'diferença sexual', diz Zizek, é real, é impossível de simbolizar, de formular como uma norma simbólica (p. 120).

Frente à dificuldade de compreensão desse conceito psicanalítico, Porchat recorre a Colette Soler, psicanalista francesa, que afirma que os anglo-saxões deveriam acompanhar Lacan em seus avanços das questões edípicas para as fórmulas da sexuação, apresentadas no Seminário $\mathrm{XX}$, intitulado Mais ainda, ditado por Lacan entre 1972 e 1973. Se em Freud as pulsões seriam unificadas pela via de identifi-cações edípicas, no Seminário XX de Lacan o que haveria seriam modos de gozo, conforme as relações estabelecidas com a linguagem a partir ou não da norma fálica. Nessas fórmulas nada prescreveria a heterossexualidade, pois qualquer um poderia se situar em qualquer posição, independente de corpo ou sexo biológico.

Para Zizek e Copjec, segundo Porchat, Butler não compreendeu as fórmulas da sexuação lacanianas e "Lacan seria mais subversivo que Butler, na opinião de Copjec." (p. 128). Butler vai responder a essas críticas dizendo acreditar ser difícil separar transcedentalismo do social e apontando os maus usos do conceito de diferença sexual de Lacan, feitos por muitos psicanalistas, que se opõem, por exemplo, à adoção de crianças por casais homoparentais, alegando que isso levaria à estruturação de crianças psicóticas.

Diante desses impasses, Butler adota a expressão "diferenças sexuais", tentando sair de uma dinâmica binária e ir para uma múltipla. Em seguida, são apresentadas as argumentações de Butler que questionam o simbólico em Lacan. O questionamento visaria verificar em que medida o conceito de simbólico corroboraria a exclusão 
de psicóticos e, por semelhança, os gêneros não inteligíveis. Para Butler as noções de parentesco em Lacan, herdeiras de Lévi-Strauss, estabeleceriam posições que regulariam o desejo dos sujeitos, excluindo formas diferentes de parentesco. Segundo Shepherdson apareceria aqui uma indistinção entre uma lei na subjetividade e uma lei da cultura ou uma confusão entre função paterna em Lacan e os papéis ocupados pelos pais da realidade ao longo da história.

Porchat conclui respondendo às questões que motivaram sua pesquisa. Afirma que com Butler compreendeu que não há consistência ontológica sustentando categorias de gênero. Assim, expõe que Butler não poderia separar-se da psicanálise, já que encontrou no conceito de pulsão uma via de compreensão que rompe com a repetição das normas de gênero. Por outro lado, a filósofa tem muitos confrontos com - Lacan estruturalista que conhece. Quiçá, dentre outras, uma possibilidade para Butler seria trabalhar com o último Lacan, aquele que teoriza priorizando o registro do real. Porchat finaliza afirmando que não se pode pensar ou fazer psicanálise sem reconhecer um posicionamento político.

Jacqueline Virmond Vieira Universidade Federal de Santa Catarina, Florianópolis, SC, Brasil

Mônica Angonese Universidade Federal de Santa Catarina, Florianópolis, SC, Brasil 